\title{
Developing capacity-building activities for mental health system strengthening in low- and middle-income countries for service users and caregivers, service planners, and researchers
}

\author{
M. Semrau ${ }^{1 *}$, A. Alem ${ }^{2}$, J. Abdulmalik ${ }^{3}$, S. Docrat ${ }^{4}$, S. Evans-Lacko ${ }^{1,5}$, O. Gureje ${ }^{3}$, F. Kigozi ${ }^{6}$, \\ H. Lempp ${ }^{7}$, C. Lund $^{1,4}$, I. Petersen ${ }^{8}$, R. Shidhaye ${ }^{9,10}$, G. Thornicroft ${ }^{1}$ and C. Hanlon ${ }^{1,2}$ \\ ${ }^{1}$ Health Service and Population Research Department, Centre for Global Mental Health, Institute of Psychiatry, Psychology and Neuroscience, \\ King's College London, London, UK \\ 2 Department of Psychiatry, School of Medicine, College of Health Sciences, Addis Ababa University, Addis Ababa, Ethiopia \\ ${ }^{3}$ Department of Psychiatry, WHO Collaborating Center for Research and Training in Mental Health, Neuroscience and Substance Abuse, \\ University of Ibadan, Ibadan, Nigeria \\ ${ }^{4}$ Department of Psychiatry and Mental Health, Alan J Flisher Centre for Public Mental Health, University of Cape Town, Cape Town, South Africa \\ ${ }^{5}$ Personal Social Services Research Unit, London School of Economics and Political Science, London, UK \\ ${ }^{6}$ Butabika National Referral and Teaching Hospital, Kampala, Uganda \\ ${ }^{7}$ Faculty of Life Sciences \& Medicine Academic Rheumatology, King's College London, London, UK \\ ${ }^{8}$ Centre for Rural Health, College of Health Sciences, University of KwaZulu-Natal, Durban, South Africa \\ ${ }^{9}$ Centre for Chronic Conditions and Injuries, Public Health Foundation of India, New Delhi, India \\ ${ }^{10}$ CAPHRI (Care and Public Health Research Institute), Maastricht University, Maastricht, The Netherlands
}

\begin{abstract}
There is increasing international recognition of the need to build capacity to strengthen mental health systems. This is a fundamental goal of the 'Emerging mental health systems in low- and middle-income countries' (Emerald) programme, which is being implemented in six low- and middle-income countries (LMICs) (Ethiopia, India, Nepal, Nigeria, South Africa, Uganda). This paper discusses Emerald's capacity-building approaches and outputs for three target groups in mental health system strengthening: (1) mental health service users and caregivers, (2) service planners and policymakers, and (3) mental health researchers. When planning the capacity-building activities, the approach taken included a capabilities/skills matrix, needs assessments, a situational analysis, systematic reviews, qualitative interviews and stakeholder meetings, as well as the application of previous theory, evidence and experience. Each of the Emerald LMIC partners was found to have strengths in aspects of mental health system strengthening, which were complementary across the consortium. Furthermore, despite similarities across the countries, capacity-building interventions needed to be tailored to suit the specific needs of individual countries. The capacity-building outputs include three publicly and freely available short courses/workshops in mental health system strengthening for each of the target groups, 27 Masters-level modules (also open access), nine Emerald-linked PhD students, two MSc studentships, mentoring of post-doctoral/mid-level researchers, and ongoing collaboration and dialogue with the three groups. The approach taken by Emerald can provide a potential model for the development of capacity-building activities across the three target groups in LMICs.
\end{abstract}

Received 30 July 2017; Accepted 2 August 2017; First published online 2 October 2017

Key words: Community mental health, health service research, mental health, minority issues and cross-cultural psychiatry, primary care.

\section{Introduction}

Capacity-building, including a focus on training, is increasingly being recognised as key to improving mental health services and systems in low- and

* Address for correspondence: M. Semrau, Health Service and Population Research Department, Centre for Global Mental Health, Institute of Psychiatry, Psychology and Neuroscience, King's College London, London, UK.

(Email: maya.semrau@kcl.ac.uk) middle-income countries (LMICs) (Thornicroft et al. 2012). Of particular importance are mental health systems' efficiency, effectiveness, equitability and ability to be tailored to the needs of people with mental health problems in these settings. The 'Emerging mental health systems in LMICs' (Emerald) programme, which aims to strengthen mental health systems in six LMICs in Africa and Asia (Ethiopia, India, Nepal, Nigeria, South Africa and Uganda) (Semrau et al. 2015; https://www.emerald-project.eu/), therefore included capacity-building as an important 
component within its larger programme. This paper describes the approach taken within Emerald to develop capacity-building activities for three target groups: (i) mental health service users and caregivers, (ii) service planners and policy-makers, and (iii) mental health researchers. In a companion editorial in this issue by Hanlon et al. (2017), the Emerald approach to evaluation of capacity-building activities is described.

\section{Capacity-building principles: theory and best practice}

\section{Mental health service users and caregivers}

There is wide recognition that involvement of service users and their caregivers in health system policy and planning processes can directly lead to improved health system strengthening (Thornicroft et al. 2002). Historically, service user involvement has been pioneered in the care of people with mental illness or HIV/AIDS in high-income countries (Tansella et al. 2014). However, there have been very few reports of efforts to involve service users and caregivers in mental health system strengthening in LMICs (Semrau et al. 2016). Participatory policy-making and planning is of particular importance in the field of mental health, where service users are uniquely vulnerable with regard to the care they receive due to the nature of their condition (Kleintjes et al. 2010). To avoid tokenistic inclusion of service users and caregivers in planning, and to facilitate patient-centric care and evidence-based co-design (Rose \& Thornicroft, 2010; Robert et al. 2015; WHO, 2016), it is necessary for professionals to work with representative organisations and facilitate effective contributions. Partnerships with service users and caregivers are understood as essential for the development of evidence-based care in government guidance across the globe (Institute of Medicine; NHMRC, 2002; DoH, 2007). They may offer one solution to the slow translation of clinical science into meaningful treatment and service development.

In the UK, current research policy and commissioning guidelines emphasise that the safety, acceptability and relevance of research can be improved through public participation. A theoretical framework of service user involvement in research consists of four interlinked main components: context (e.g., trends of health care practice and research, health policy, concepts of involvement/participation); methods (e.g., working relationships, paying attention to who and when to involve service users, planning and costing the involvement); roles (e.g., different types of research roles for service users, personal skills and capacity- building) and outcomes (e.g., types of outcome relevant to service users, recognising the impact, recording impact) (Smith et al. 2008; Morrow et al. 2012). Service user involvement in research has also been conceptualised into a framework, which considers the level and stage of involvement (Morrow et al. 2012). Both level and stage of involvement can be combined, for example, level of involvement can vary (minimal, consultation, collaboration or service user led/controlled) across each stage of the research cycle (development of research idea, commissioning, research design, monitoring of the research, data analysis, interpretation of findings). This framework was found to be useful within Emerald for assessing involvement, and was extended beyond research to consider policy-making, service planning and development, and service monitoring or quality improvement.

\section{Service planners and policy-makers}

There is little information available in the literature on capacity-building of this group (Keynejad et al. 2016). Overall, the need to build capacity for policy-makers and planners in planning mental health services has been recognised (Keynejad et al. 2016), as well as the need to adopt a population mental health approach, making use of the best available data and resources, and aligning mental health needs with other health priorities in an integrated service delivery framework. Leadership has been argued to be the key ingredient of mental health system strengthening in LMICs from which all other capacity-building can flow (Beinecke et al. 2010; Minas, 2012; Abdulmalik et al. 2014); however, in reality few policy-makers who make decisions about mental health needs, resources, plans and implementation have a mental health background and usually have a modest understanding of the specific system challenges for mental health. Mental health units (e.g., on a regional or national level) tend to be small and under-resourced, with little decision-making authority, and little capacity for developing and implementing mental health policies and systems (Thornicroft et al. 2012).

\section{Mental health researchers}

Mental health research is an essential component to support mental health system strengthening in LMICs (Saxena et al. 2011; Betancourt \& Chambers, 2016). The expropriation of research expertise from LMICs to high-income settings (or 'brain drain') is a continuing threat to the viability of research capacity in LMICs (Evans-Lacko et al. 2016).

A previous review identified challenges, priorities and evidence-based strategies for building capacity of 
mental health researchers in LMICs (Thornicroft et al. 2012). Examples included recommendations by the multi-country Mental Health and Poverty Project (MHaPP) (Flisher et al. 2007), which had a strong capacity-building element linked to health policy research (Thornicroft et al. 2012). This review provided a set of guiding principles for capacity-building within Emerald: (i) focus training within LMICs and as locally available as possible; (ii) seek reciprocity in NorthSouth and South-South relationships; (iii) define clear output and outcome indicators to monitor success; (iv) focus on all levels of researchers (senior as well as junior); (v) develop in-country expertise through 'Training of Trainers' courses; (vi) link training to the phases of the research project; (vii) mentor junior researchers across sites and (viii) use multiple means for communication including face-to-face site visits to research centres.

\section{Approaches to developing capacity-building outputs within Emerald}

Overall, the development of capacity-building activities was guided by a principle of collaboration amongst the Emerald partners, in line with the guiding principles identified in the review by Thornicroft et al. (2012), as well as by the principles of appropriateness, reciprocity and sustainability.

The approaches taken by Emerald to the development of the capacity-building activities were similar across the three target groups and included similar methodologies. Table 1 shows the various approaches that were taken for the three groups. Whilst this editorial provides a brief overview of the findings of the approaches outlined in Table 1, a more detailed report (including country-level data) is available from the authors.

As a starting point, at baseline, the existing skills and capabilities present amongst each of the Emerald
LMIC partners were mapped through a form. This ensured that the capacity-building plans drew fully on the rich resources available. We found that the Emerald consortium included a wealth of complementary expertise and experience that could be utilised for developing capacity-building materials in different aspects of mental health system strengthening, such as mental health systems research or mental health service user involvement. Opportunities for South-South and North-South collaboration for capacity-building to strengthen mental health systems were also identified. The variation in LMIC partners' skills and capacities drew out the importance of assessing their needs and resources on a country level.

\section{Mental health service users and caregivers}

The approach taken by Emerald to develop capacitybuilding for this group is presented in Fig. 1.

This included a situational analysis (scoping exercise), the aim of which was to gain an overall appreciation of the baseline situation in each of the Emerald countries. This included the extent of mental health service user and caregiver involvement across various aspects of mental health systems, which then informed assessment of the capacity-building needs of this group to promote mental health system strengthening. A form was completed by the Emerald LMIC partners for this, in consultation with service user and caregiver organisations.

Assessment of the capacity-building needs of mental health service users and caregivers in order to support greater involvement was considered to be complex by the Emerald LMIC partners and to warrant a more systematic and in-depth approach than the initial situation analysis. Due to a lack of an existing evidence base in the literature, a systematic review was conducted within Emerald of evaluations of capacity-building interventions for mental health service

Table 1. Approaches taken during development of capacity-building outputs within Emerald

\begin{tabular}{lccc}
\hline & $\begin{array}{c}\text { Mental health service } \\
\text { users and caregivers }\end{array}$ & $\begin{array}{c}\text { Service planners } \\
\text { and policy-makers }\end{array}$ & $\begin{array}{c}\text { Mental health } \\
\text { researchers }\end{array}$ \\
\hline $\begin{array}{l}\text { Previous theoretical frameworks } \\
\text { Previous evidence in literature }\end{array}$ & $\mathrm{X}$ & $\mathrm{X}$ \\
Previous experiences of capacity-building within other projects & $\mathrm{X}$ & $\mathrm{X}$ & $\mathrm{X}$ \\
Capabilities/skills matrix & & $\mathrm{X}$ & $\mathrm{X}$ \\
Needs assessment & $\mathrm{X}$ & $\mathrm{X}$ \\
Situational analysis/scoping exercise & $\mathrm{X}$ & $\mathrm{X}$ & $\mathrm{X}$ \\
Systematic review & $\mathrm{X}$ & $\mathrm{X}$ & \\
Qualitative stakeholder interviews & & $\mathrm{X}$ \\
Stakeholder meetings & & \\
\hline
\end{tabular}




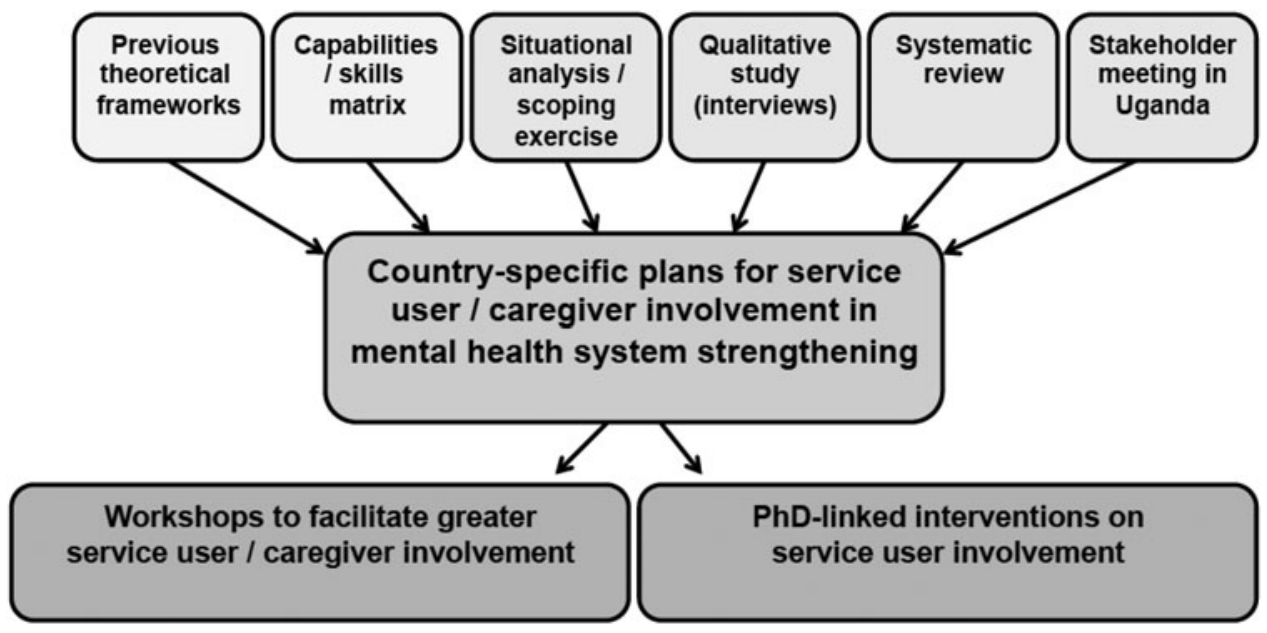

Fig. 1. Approach taken to developing the Emerald capacity-building plans for mental health service users and caregivers.

users in LMICs (Semrau et al. 2016). Furthermore, a qualitative study of service users, caregivers and representative organisations was carried out to characterise capacity-building needs (see Lempp et al. 2017), and a multi-country stakeholder meeting was held in Uganda to bring together evidence and experience.

\section{Service planners and policy-makers}

The approach taken by Emerald to develop capacitybuilding for this group is presented in Fig. 2 .

A needs assessment was conducted, which was linked to in-depth interviews that were being carried out for another objective within Emerald (Petersen et al. 2017). A purposively selected sample was included (intended to yield the most pertinent perspectives for the country concerned) of 115 policy-makers, planners and service developers across the six Emerald countries (ranging between 16 and 29 respondents in each country) who were asked about capacity-building needs and priorities across a range of mental health system strengthening topics.

The needs assessment showed that there was insufficient evidence readily available to inform the capacity-building activities for service planners and policy-makers. A systematic review of the evidence base was therefore carried out in order to inform development of the most effective capacity-building activities for mental health system strengthening for this group (Keynejad et al. 2016). Valuable input was also obtained from Ministry of Health colleagues in Ethiopia and Uganda, and the Nigeria Emerald team provided their expertise in mental health leadership and advocacy by drawing on the ongoing Mental Health Leadership and Advocacy Programme (mhLAP) in that partner country (Abdulmalik et al. 2014). In Nepal and Ethiopia, there was a continuous process of relationship development with service

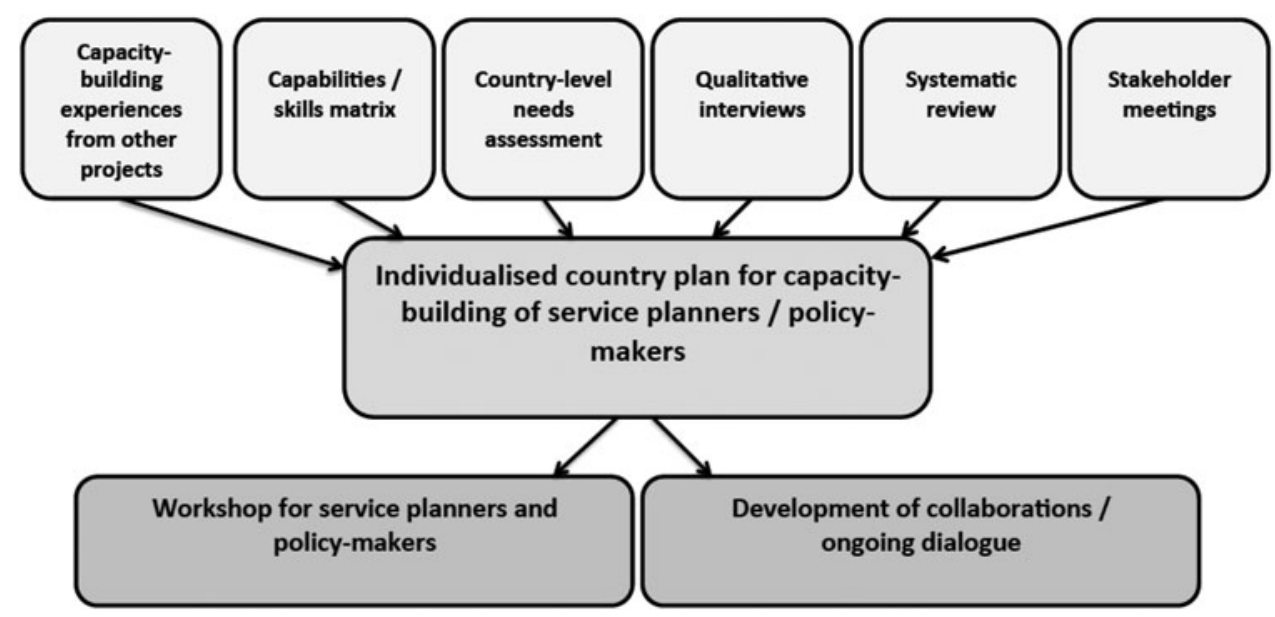

Fig. 2. Approach taken to developing the Emerald capacity-building plans for service planners and policy-makers. 
planners and policy-makers, including a stakeholders' meeting as part of an Emerald consortium meeting in Nepal in September 2016.

\section{Mental health researchers}

The overall approach taken by Emerald for capacitybuilding of this group is presented in Fig. 3.

The capacity-building context for this target group included other capacity-building programmes for LMIC researchers, such as those linked to the 'Programme for Improving Mental health carE' (PRIME) (involving Emerald partners in Ethiopia, India, Nepal, South Africa and Uganda) (Lund et al. 2012), the 'Africa Focus on Intervention Research for Mental health' (AFFIRM) project (involving Emerald partners in Ethiopia and South Africa) (Lund et al. 2015), the Partnership for Mental Health Development in Sub-Saharan Africa (PaM-D) project (involving the Nigeria Emerald country partner) and the mhLAP programme (Abdulmalik et al. 2014).

Unlike previous capacity-building work, Emerald aimed to equip mental health researchers with general health service and system research skills that were applicable to other health conditions, and explicitly drawing out the similarities amongst approaches required for research into health care for other noncommunicable diseases and chronic communicable conditions, such as HIV/AIDS. This approach maximised researchers' understanding of the public health context and relevance of mental health in LMICs, helping to overcome the marginalisation of mental health research.

In order to reflect the expected variety in the existing capabilities of the participating countries for mental health research, a needs assessment of each of the Emerald LMIC partners was conducted. This included a narrative description of the mental health research capacity-building needs, a SWOT analysis (identification of strengths, weaknesses, opportunities and threats) of the state of mental health research, existing Masters-level training in health systems and services research, existing PhD-level training in health systems and services research, the mentoring needs of departmental mid-level researchers, and broader institutional capacity-building and short courses, in keeping with recognised best practices in building mental health research capacity (Thornicroft et al. 2012).

Lessons learned - moving towards the development of capacity-building outputs

\section{Mental health service users and caregivers}

The situational analysis showed that the Emerald LMIC partners differed substantially in their level of involvement of service users and caregivers, which is why a country-specific multi-faceted approach was taken (see Table 2). Across the six countries, there were 14 organisations for service users with mental, neurological or substance use disorders (ranging between zero in Ethiopia and four each in Nepal and South Africa), and 17 caregiver organisations (ranging between one in Ethiopia and Nigeria and eight in India). At the low end of the scale of service user/caregiver involvement, in Ethiopia the single caregiver organisation was based in the capital city and had fewer than 300 members. In contrast, Uganda had three service user organisations with high levels of membership (16900) spread throughout the country (see Lempp et al. 2017).

The situation analysis also revealed that the aims of the service user organisations were clearly articulated, with most including advocacy and awareness-raising within their remit. However, although service users

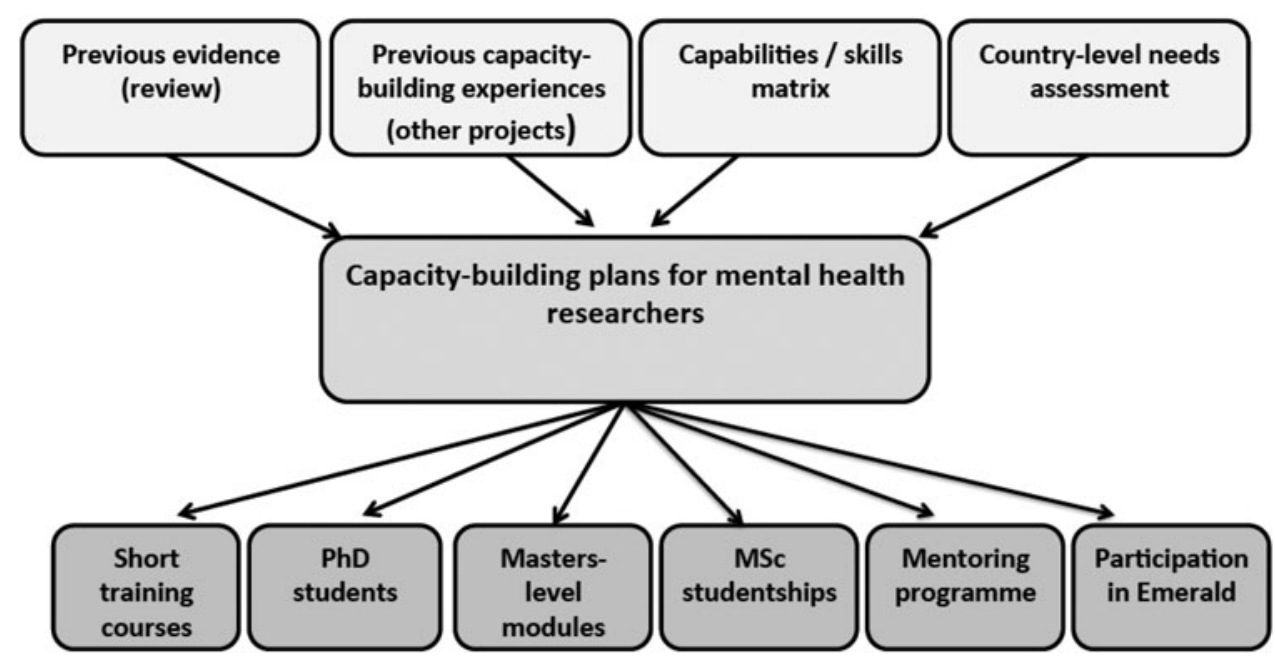

Fig. 3. Approach taken to developing the Emerald capacity-building plans for mental health researchers. 
Table 2. The Emerald programme's capacity-building outputs

\begin{tabular}{|c|c|c|}
\hline Target groups & $\begin{array}{l}\text { Interventions for mental health } \\
\text { system strengthening }\end{array}$ & Further details \\
\hline \multirow{9}{*}{$\begin{array}{l}\text { Mental health } \\
\text { service users } \\
\text { and caregivers }\end{array}$} & $\begin{array}{l}\text { Country-specific, multi-faceted } \\
\text { approach }\end{array}$ & See section on 'Lessons learned' \\
\hline & $\begin{array}{l}\text { Workshops for service users and } \\
\text { caregivers to raise awareness }\end{array}$ & $\begin{array}{l}\text { Half-day workshop. The materials can be customised to meet country's } \\
\text { specific needs and priorities. The specific aims of the workshop are: }\end{array}$ \\
\hline & $\begin{array}{l}\text { and mobilise for greater } \\
\text { advocacy and involvement }{ }^{\mathrm{a}}\end{array}$ & $\begin{array}{l}\text { 1. Raising awareness about mental health and illness and treatment } \\
\text { models }\end{array}$ \\
\hline & & 2. Raising awareness about rights of people with mental illness \\
\hline & & 3. Establishing a network of service users and caregivers \\
\hline & & $\begin{array}{l}\text { 4. Starting a conversation about involvement in mental health services } \\
\text { and systems }\end{array}$ \\
\hline & & $\begin{array}{l}\text { Within Emerald, the workshop has been delivered four times in total } \\
\text { across the LMIC partners. }\end{array}$ \\
\hline & $\begin{array}{l}\text { Workshops for primary care } \\
\text { workers and managers to } \\
\text { support greater involvement of } \\
\text { service users }\end{array}$ & $\begin{array}{l}\text { See short course for mental health researchers below on 'Involving } \\
\text { service users and caregivers in research and policy strengthening'. }\end{array}$ \\
\hline & $\begin{array}{l}\text { PhD-linked interventions to } \\
\text { develop and pilot models of } \\
\text { service user involvement in } \\
\text { mental health system } \\
\text { strengthening }\end{array}$ & $\begin{array}{l}\text { PhD theses are being conducted within Emerald on service user } \\
\text { involvement (also see below), which are part of the broader } \\
\text { programme within Emerald to promote involvement of service users. }\end{array}$ \\
\hline \multirow[t]{8}{*}{$\begin{array}{l}\text { Service planners } \\
\text { and policy- } \\
\text { makers }\end{array}$} & \multirow[t]{6}{*}{$\begin{array}{l}\text { Workshops focused on mental } \\
\text { health awareness-raising, the } \\
\text { chronic care model and mental } \\
\text { health system planning }\end{array}$} & $\begin{array}{l}\text { Modular training short course for health care planners (assumed to be } \\
\text { non-mental health specialists) in health systems for chronic disorders } \\
\text { in LMICs (focusing on mental health systems). The short course can } \\
\text { be delivered en bloc over two days or delivered as separate } \\
\text { components over a longer period of time, and includes three modular } \\
\text { elements: }\end{array}$ \\
\hline & & - Health system strengthening for chronic disorders (1/2 day) \\
\hline & & - Integrated collaborative chronic care (1/2 day) \\
\hline & & - Mental health service planning and implementation (1 day) \\
\hline & & $\begin{array}{l}\text { The short course is envisaged to be implemented in the context of an } \\
\text { ongoing dialogue and knowledge exchange with policy-makers and } \\
\text { planners, and is ideally meant to be embedded within ongoing } \\
\text { contact, mentoring and technical support to short course trainees in } \\
\text { order to consolidate learning and build up a collaborative } \\
\text { relationship for mental health system strengthening. }\end{array}$ \\
\hline & & $\begin{array}{l}\text { Within Emerald, the course has been delivered five times in total across } \\
\text { the LMIC partners. }\end{array}$ \\
\hline & \multirow{2}{*}{$\begin{array}{l}\text { Ongoing dialogue and developing } \\
\text { collaborations with the aim of } \\
\text { providing technical support and } \\
\text { increasing capacity over time }\end{array}$} & $\begin{array}{l}\text { This tied in with the short courses (see above) in some LMIC partners, } \\
\text { for example, in Nepal the short courses were structured across } \\
\text { repeated contacts. }\end{array}$ \\
\hline & & $\begin{array}{l}\text { An example of technical support provided to service planners is training } \\
\text { in the OneHealth tool, which is an online platform for human } \\
\text { resource and financial planning (Chisholm et al. 2016). }\end{array}$ \\
\hline
\end{tabular}


Table 2. Continued

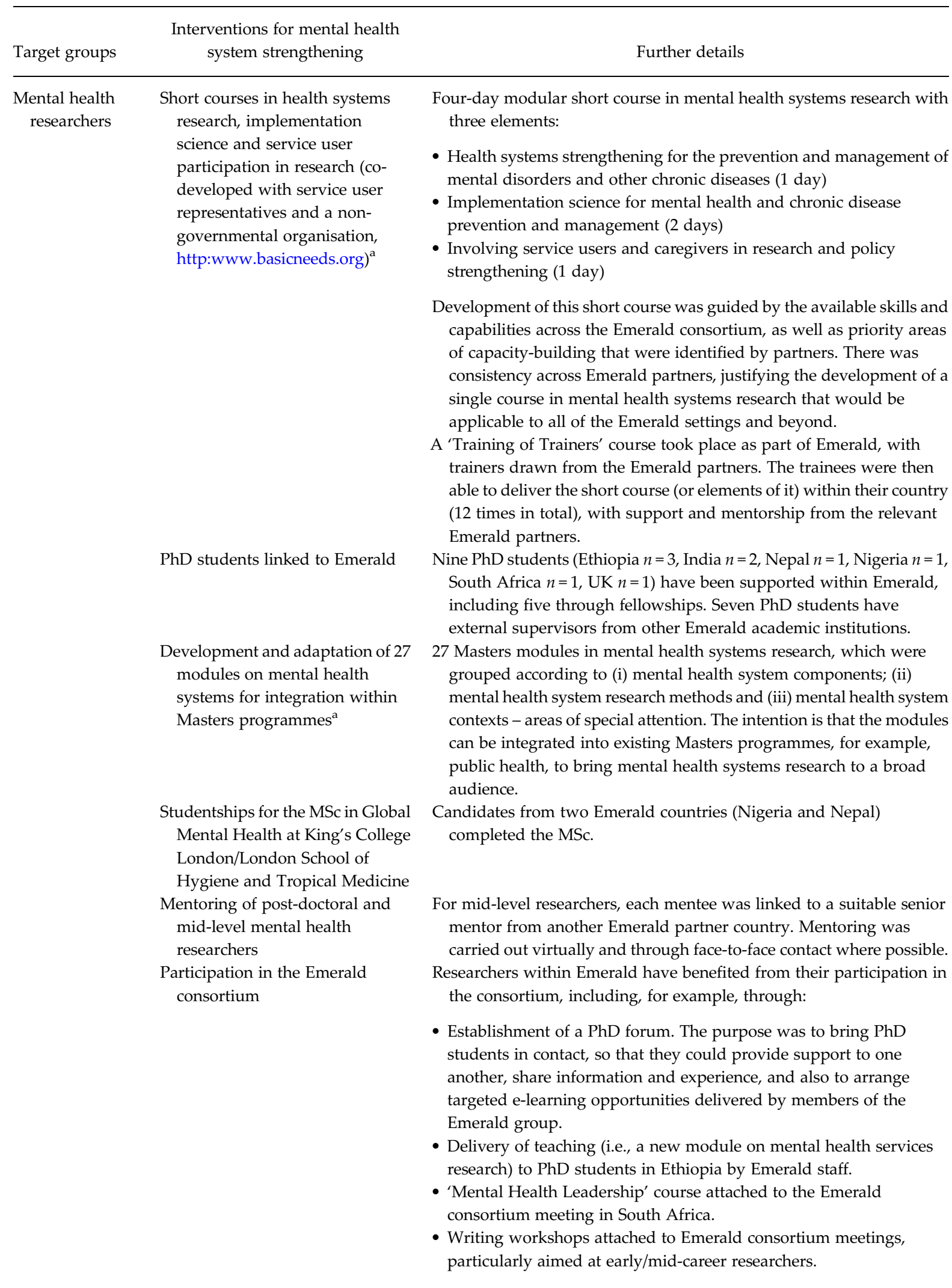

${ }^{\text {a }}$ Can be accessed at via the King's College London website 
and caregivers had some involvement in mental health system strengthening, the stage and level of involvement was minimal in all Emerald countries and, at best, consultative, but rarely collaborative and almost never service-user controlled. Within mental health research, most often participation was in the process of research rather than grant applications, design, analysis, dissemination or ethics applications. Service user involvement in policy-making, planning, service monitoring and quality control was mostly linked to awareness-raising or advocacy and rarely to service development or quality control. The Uganda team reported the highest level of service user and caregiver involvement, with collaboration occurring with respect to both policy-making and service co-ordination, delivery and monitoring. South Africa and India reported limited examples of a collaborative involvement only in the area of policy-making. None of the country teams were aware of any examples of service user-led involvement in aspects of mental health system strengthening. Key ingredients across Emerald LMIC partners were therefore a need to create awareness and reduce stigma, and to inform, mobilise and engage service users before proceeding to specific capacity-building training interventions.

The qualitative study underlined the additional challenges faced by LMICs in moving towards greater service user involvement, particularly with respect to low levels of mental health literacy, low levels of empowerment, strong power imbalances between health care providers and service users, a lack of mobilisation of service users at the grass root level and the pervasive issue of poverty. Balanced against this was a strong desire from many caregivers and service users for greater involvement and influence over the development of mental health services and service monitoring and quality control. The value of involvement in mental health research was also endorsed strongly in the Emerald LMIC partners where service users and caregivers had direct experience of involvement as research subjects (see Lempp et al. 2017).

Whilst the systematic review identified promising strategies for service user or caregiver involvement, particularly in the realm of advocacy, there was a dearth of evidence to support the effectiveness of one approach over another (Semrau et al. 2016).

\section{Service planners and policy-makers}

Within the needs assessment (qualitative interviews), almost all aspects of capacity-building for mental health system strengthening were prioritised by respondents. However, respondents found it challenging to be specific about their training needs because of low baseline competency levels. In line with other publications (Beinecke et al. 2010; Minas, 2012), leadership was highly prioritised. However, respondents also endorsed the relevance of capacity-building in specific skill areas of mental health systems, including planning, human resource projections, anti-stigma activity, health management information systems for mental health, monitoring and evaluating mental health systems, advocacy and promoting greater involvement of mental health service users and caregivers.

The systematic review found a lack of high-quality evidence for capacity-building interventions for this group, highlighting the need for partnership approaches, which should be assessed rigorously against prespecified conceptual frameworks and hypotheses, and utilising longitudinal evaluation and mixed quantitative and qualitative approaches (Keynejad et al. 2016).

\section{Mental health researchers}

The SWOT analysis suggested that the Emerald LMIC partners differed in their baseline strengths, weaknesses, opportunities and threats to mental health systems research, with variability in institutional support, research culture and research infrastructure. Specific strengths and opportunities included the existence of ongoing international collaborations, whilst weaknesses and threats often related to administrative and logistical issues and the wider research culture. The needs assessment also identified priority areas of focus for researchers at various stages in their careers. The overwhelming preference was for capacitybuilding activities to take place within each Emerald country in order to expand the reach of activities and ensure sustainability.

Furthermore, the needs assessment showed that there was a strong desire amongst the Emerald LMIC partners to develop opportunities for postgraduate degrees in mental health system strengthening, including Masters, $\mathrm{PhD}$ and post-doctoral researchers. This was the case both for academic and non-academic Emerald partners. The academic (University) institutions within Emerald were all interested in developing modules on mental health system strengthening to be integrated into existing Masters programmes, for example, in public health or health promotion and illness prevention. Development of postgraduate training opportunities in-country was found to be critical for stemming 'brain drain'. Integration of mental health systems research modules into existing Masters programmes was thought to help to reach students with a broader range of backgrounds, including public health, health economics, social work, psychology or management, which is appropriate and necessary for such a cross-cutting, multi-sectoral field as health systems research. Individuals with broader Masters 
training (rather than mental health-specific systems research) might be expected to be more marketable and better meet country needs for more broadly skilled and versatile personnel. Moreover, it was suggested that a Masters programme that is narrowly focused on mental health systems might struggle to attract applicants due to the under-recognition of mental health issues and the stigma surrounding mental health.

For non-academic partners within Emerald, the development of postgraduate training programmes to be delivered within their organisations was not possible or appropriate, but there was great interest to benefit from such programmes in neighbouring countries (e.g., Nepal and India), particularly if distance-based learning opportunities were available. Building mental health research capacity amongst those partners that implemented services was considered to provide an important opportunity to integrate mental health systems research into programming and planning, with the hope that the findings of mental health systems evaluations could speedily and effectively strengthen the system.

Realising the importance of mid-level mental health researchers to a sustainable research environment and culture, and the relative neglect of this cadre of researchers in capacity-building activities, the mentoring of post-doctoral researchers in the partner organisations was given priority within Emerald. Such researchers are often thrust into administrative and academic leadership roles too early and may not receive sufficient support in their career development to allow them to reach full potential. Often, this leads to frustrations and increased temptation to leave for more nurturing settings in high-income countries. The Emerald capacity-building needs assessment identified the particular requirements of this group of mental health researchers, for example, in grant writing and academic career development.

\section{Capacity-building outputs within Emerald}

The findings and lessons learned within Emerald led to the development of several capacity-building activities and outputs. These are displayed in Table 2, as well as in Figs 1-3 for each of the three target groups.

All training materials developed for the three target groups (i.e., short courses, workshops and Masters modules) are publicly and freely available online under a Creative Commons licence (via the King's College London website).

\section{Conclusion}

The Emerald programme included the development of capacity-building activities in mental health system strengthening for (1) mental health service users and caregivers, (2) service planners and policy-makers, and (3) mental health researchers in LMICs. The systematic and comprehensive approach taken by Emerald confirmed the need to build capacity amongst these three diverse groups and the impact that it can have on improving access to patient-centric care in low-resource settings. The process led to a multifaceted and diverse range of capacity-building outputs, including three short courses for the three target groups, as well as 27 Masters modules in mental health system strengthening, which are freely accessible to all (via the King's College London website). These materials fill an important gap in capacity-building for mental health system strengthening and may provide a valuable resource for LMICs worldwide.

\section{Acknowledgements}

The partner organisations involved in the Emerald programme are Addis Ababa University (AAU), Ethiopia; Butabika National Mental Hospital (BNH), Uganda; ARTTIC, Germany; HealthNet TPO, The Netherlands; King's College London (KCL), UK; Public Health Foundation of India (PHFI), India; Transcultural Psychosocial Organization Nepal (TPO Nepal), Nepal; Universidad Autonoma de Madrid (UAM), Spain; University of Cape Town (UCT), South Africa; University of Ibadan (UI), Nigeria; University of KwaZulu-Natal (UKZN), South Africa; and World Health Organization (WHO), Switzerland. The Emerald programme is led by Professor Sir Graham Thornicroft at KCL. The project coordination group consists of Professor Atalay Alem (AAU), Professor José Luis Ayuso-Mateos (UAM), Dr Dan Chisholm (WHO), Dr Stefanie Fülöp (ARTTIC), Professor Oye Gureje (UI), Dr Charlotte Hanlon (AAU), Dr Mark Jordans (War Child; TPO Nepal; KCL), Dr Fred Kigozi (BNH), Professor Crick Lund (UCT), Professor Inge Petersen (UKZN), Dr Rahul Shidhaye (PHFI) and Professor Sir Graham Thornicroft (KCL). Parts of the programme were also coordinated by Ms Shalini Ahuja (PHFI), Dr Jibril Omuya Abdulmalik (UI), Ms Kelly Davies (KCL), Ms Sumaiyah Docrat (UCT), Dr Catherine Egbe (UKZN), Dr Sara Evans-Lacko (KCL), Dr Margaret Heslin (KCL), Dr Dorothy Kizza (BNH), Ms Lola Kola (UI), Dr Heidi Lempp (KCL), Dr Pilar López (UAM), Ms Debra Marais (UKZN), Ms Blanca Mellor (UAM), $\mathrm{Mr}$ Durgadas Menon (PHFI), Dr James Mugisha (BNH), Ms Sharmishtha Nanda (PHFI), Dr Anita Patel (KCL), Ms Shoba Raja (BasicNeeds, India; KCL), Dr Maya Semrau (KCL), Mr Joshua Ssebunya (BNH), Mr Yomi Taiwo (UI) and Mr Nawaraj Upadhaya 
(TPO Nepal). The Emerald programme's scientific advisory board includes A/Professor Susan Cleary (UCT), Dr Derege Kebede (WHO, Regional Office for Africa), Professor Harry Minas (University of Melbourne, Australia), Mr Patrick Onyango (TPO Uganda), Professor Jose Luis Salvador Carulla (University of Sydney, Australia) and Dr R Thara (Schizophrenia Research Foundation (SCARF), India). The following individuals were members of the Emerald consortium: Dr Kazeem Adebayo (UI), Ms Jennifer Agha (KCL), Ms Ainali Aikaterini (WHO), Dr Gunilla Backman (London School of Hygiene and Tropical Medicine; KCL), Mr Piet Barnard (UCT), Dr Harriet Birabwa (BNH), Ms Erica Breuer (UCT), Mr Shveta Budhraja (PHFI), Amit Chaturvedi (PHFI), Mr Daniel Chekol (AAU), Mr Naadir Daniels (UCT), Mr Bishwa Dunghana (TPO Nepal), Ms Gillian Hanslo (UCT), Ms Edith Kasinga (UCT), Ms Tasneem Kathree (UKZN), Mr Suraj Koirala (TPO Nepal), Professor Ivan Komproe (HealthNet TPO), Dr Mirja Koschorke (KCL), $\mathrm{Mr}$ Domenico Lalli (European Commission), $\mathrm{Mr}$ Nagendra Luitel (TPO Nepal), Dr David McDaid (KCL), Ms Immaculate Nantongo (BNH), Dr Sheila Ndyanabangi (BNH), Dr Bibilola Oladeji (UI), Professor Vikram Patel (KCL), Ms Louise Pratt (KCL), Professor Martin Prince (KCL), Ms M Miret (UAM), Ms Warda Sablay (UCT), Mr Bunmi Salako (UI), Dr Tatiana Taylor Salisbury (KCL), Dr Shekhar Saxena (WHO), Ms One Selohilwe (UKZN), Dr Ursula Stangel (GABO:mi), Professor Mark Tomlinson (UCT), Dr Abebaw Fekadu (AAU) and Ms Elaine Webb (KCL).

\section{Financial Support}

The research leading to these results is funded by the European Union's Seventh Framework Programme (FP7/2007-2013) under grant agreement no 305968. The funder had no role in study design, data collection and analysis, decision to publish, or preparation of the manuscript.

\section{Conflict of Interest}

GT is supported by the National Institute for Health Research (NIHR) Collaboration for Leadership in Applied Health Research and Care South London at King's College London NHS Foundation Trust. The views expressed are those of the author(s) and not necessarily those of the NHS, the NIHR or the Department of Health. GT acknowledges financial support from the Department of Health via the National Institute for Health Research (NIHR) Biomedical Research Centre and Dementia Unit awarded to South London and Maudsley NHS
Foundation Trust in partnership with King's College London and King's College Hospital NHS Foundation Trust. GT is supported by the European Union Seventh Framework Programme (FP7/2007-2013) Emerald project. SEL has received consulting fees from Lundbeck. No other conflicts of interest were declared.

\section{Ethical Standard}

The authors assert that all procedures contributing to this work comply with the ethical standards of the relevant national and institutional committees on human experimentation and with the Helsinki Declaration of 1975, as revised in 2008.

\section{Availability of Data and Materials}

The data supporting the findings of this paper can be obtained from the authors.

\section{References}

Abdulmalik J, Fadahunsi W, Kola L, Nwefoh E, Minas H, Eaton J, Gureje O (2014). The Mental Health Leadership and Advocacy Program (mhLAP): a pioneering response to the neglect of mental health in Anglophone West Africa. International Journal of Mental Health Systems 8, 5. doi: 10.1186/1752-4458-8-5.

Beinecke RH, Minas H, Goldsack S, Peters J (2010). Global mental health leadership training programmes. The International Journal of Leadership in Public Services 6(Suppl.), 63-72.

Betancourt TS, Chambers DA (2016). Optimizing an era of global mental health implementation science. JAMA Psychiatry 73, 99-100.

Chisholm D, Heslin M, Docrat S, Nanda S, Shidhaye R, Upadhaya N, Jordans M, Abdulmalik J, Olayiwola $S$, Gureje O, Kizza D, Mugisha J, Kigozi F, Hanlon C, Adugna M, Sanders R, Pretorius C, Thornicroft G, Lund C (2016). Scaling-up services for psychosis, depression and epilepsy in Sub-Saharan Africa and South Asia: development and application of a mental health systems planning tool (OneHealth). Epidemiology and Psychiatric Sciences 19, 1-11.

Department of Health (DoH) (2007). Best Research for Best Health. A New National Health Research Strategy. Department of Health: London.

Evans-Lacko S, Ribeiro W, Brietzke E, Knapp M, Mari J, McDaid D, Paula C, Romeo R, Thornicroft G, Wissow L (2016). Lean economies and innovation in mental health systems. Lancet 387, 1356-1358.

Flisher AJ, Lund C, Funk M, Banda M, Bhana A, Doku V, Drew N, Kigozi F, Knapp M, Omar M, Petersen I, Green A (2007). Mental health policy development and implementation in four African countries. Journal of Health Psychology 12, 505-516. 
Hanlon C, Semrau M, Alem A, Abayneh S, Abdulmalik J, Docrat S, Evans-Lacko S, Gureje O, Jordans M, Lempp H, Mugisha J, Petersen I, Shidhaye R, Thornicroft G (2017). Evaluating capacity-building for mental health system strengthening in low- and middle-income countries for service users and caregivers, service planners and researchers. Epidemiology and Psychiatric Sciences (This issue). doi: 10.1017/S2045796017000440.

Institute of Medicine (IOM). (http://www.iom.edu.np/). Accessed 24 July 2017.

Keynejad R, Semrau M, Toynbee M, Evans-Lacko S, Lund C, Gureje O, Ndyanabangi S, Courtin E, Abdulmalik JA, Alem A, Fekadu A, Thornicroft G, Hanlon C (2016). Building the capacity of policy-makers and planners to strengthen mental health systems in low- and middleincome countries: a systematic review. BMC Health Services Research 16, 601.

Kleintjes S, Lund C, Swartz L, Flisher AJ, The MHaPP Research Programme Consortium (2010). Mental health care user participation in mental health policy development and implementation in South Africa. International Review of Psychiatry 22, 568-577.

Lempp H, Abayneh S, Gurung D, Kola L, Abdulmalik J, Evans-Lacko S, Semrau M, Alem A, Thornicroft G, Hanlon C (2017). Service user and caregiver involvement in mental health system strengthening in low and middle income countries: a cross-country qualitative study. Epidemiology and Psychiatric Sciences (This issue).

Lund C, Tomlinson M, De Silva M, Fekadu A, Shidhaye R, Jordans M, Petersen I, Bhana A, Kigozi F, Prince $M$, Thornicroft G, Hanlon C, Kakuma R, McDaid D, Saxena S, Chisholm D, Raja S, Kippen-Wood S, Honikman S, Fairall L, Patel V (2012). PRIME: a programme to reduce the treatment gap for mental disorders in five low- and middle-income countries. PLoS Medicine 9, e1001359.

Lund C, Alem A, Schneider M, Hanlon C, Ahrens J, Bandawe C, Bass J, Bhana A, Burns J, Chibanda D, Cowan F, Davies T, Dewey M, Fekadu A, Freeman M, Honikman S, Joska J, Kagee A, Mayston R, Medhin G, Musisi S, Myer L, Ntulo T, Nyatsanza M, Ofori-Atta A, Petersen I, Phakathi S, Prince M, Shibre T, Stein DJ, Swartz L, Thornicroft G, Tomlinson M, Wissow L, Susser E (2015). Generating evidence to narrow the treatment gap for mental disorders in sub-Saharan Africa: rationale, overview and methods of AFFIRM. Epidemiology and Psychiatric Sciences 24, 233-240.

Minas H (2012). The centre for international mental health approach to mental health system development. Harvard Review of Psychiatry 20, 37-46.

Morrow E, Boaz A, Brearley S, Ross F (2012). Handbook of Service User Involvement in Nursing and Healthcare Research. Wiley-Blackwell: Chichester.

National Health and Medical Research Council (2002). The NHMRC Strategic Plan 2000-2003 (http://www.nhmrc.gov. au/guidelines/publications/nh132). Commonwealth of Australia. Accessed 24 July 2017.

Petersen I, Marais D, Abdulmalik J, Ahuja S, Alem A, Chisholm D, Egbe C, Gureje O, Hanlon C, Lund C, Shidhaye R, Jordans M, Kigozi F, Mugisha J, Upadhaya N, Thornicroft G (2017). Strengthening mental health system governance in six low- and middle-income countries in Africa and South Asia: challenges, needs and potential strategies. Health Policy and Planning 32, 699-709. doi: 10.1093/heapol/czx014.

Robert G, Cornwell J, Locock L, Purushotham A, Sturmey G, Gager M (2015). Patients and staff as codesigners of healthcare services. British Medical Journal 350, g7714.

Rose D, Thornicroft G (2010). Service user perspectives on the impact of a mental illness diagnosis. Epidemiologia e Psichiatria Sociale 19, 2.

Saxena S, Lora A, Morris J, Berrino A, Esparza P, Barrett T, van Ommeren M, Saraceno B (2011). Mental health services in 42 low- and middle-income countries: a WHOAIMS cross-national analysis. Psychiatric Services 62, 123-125.

Semrau M, Evans-Lacko S, Alem A, Ayuso-Mateos JL, Chisholm D, Gureje O, Hanlon C, Jordans M, Kigozi F, Lempp H, Lund C, Petersen I, Shidhaye R, Thornicroft G (2015). Strengthening mental health systems in low and middle-income countries: the Emerald programme. BMC Medicine 13, 79.

Semrau M, Lempp H, Keynejad R, Evans-Lacko S, Mugisha J, Raja S, Lamichhane J, Alem A, Thornicroft G, Hanlon C (2016). Service user and caregiver involvement in mental health system strengthening in low- and middle-income countries: systematic review. BMC Health Services Research 16, 79. doi: 10.1186/s12913-016-1323-8.

Smith E, Ross F, Donovan S, Manthorpe J, Brearley S, Sitzia J, Beresford P (2008). Service user involvement in nursing, midwifery and health visiting research. A review of evidence and practice. International Journal of Nursing Studies 45, 298-315.

Tansella M, Thornicroft G, Lempp L (2014). Lessons from community mental health to drive implementation in health care systems for people with long-term conditions. International Journal of Environmental Research in Public Health 11, 4714-4728.

Thornicroft G, Rose D, Huxley P, Dale G, Wykes T (2002). What are the research priorities of mental health service users? Journal of Mental Health 11, 1-5.

Thornicroft G, Cooper S, van Bortel T, Kakuma R, Lund C (2012). Capacity building in global mental health research. Harvard Review of Psychiatry 20, 13-24.

World Health Organization (WHO) (2016). Framework on integrated, people-centred health services, Sixty-ninth World Health Assembly - Report, 15 April 2016 (http:// apps.who.int/gb/ebwha/pdf_files/WHA69/A69_39-en.pdf? ua=1). Accessed 24 July 2017. 